\title{
XI.-NOTES AND NEWS.
}

\section{"HYPOTHETICALS IN A CONTEXT."}

There is an interesting contradiction, in result, between Mr Johnson's answer and mine (in the previous No. of $\mathbf{M i n d}$ ) to the main question raised by "Lewis Carroll." Perhaps it may be removed, or minimised, in the following manner.

My contention is, not that the sentence 'If $A$ is true, $B$ is not true' must on all occasions mean something more than 'the conjunction of $A$ with $B$ is false,' but that in the context in which it is here placed, it requires to be taken in a less negative sense than this, -at least in the absence of a special warning that its meaning is to be thus limited.

As the consequent of a hypothetical, it is expressly given as possibly false, whereas the other hypothetical (2) is given as certainly true. The effect of this context, it seems to me, is to oblige us to decide the question (whether these sentences have compatible meanings) as adversely as possible, not as favourably as possible, to the truth of the consequent 'If $A$, then not $B .^{\prime} \quad$ We are challenged to find the most, not the least, that is involved in the given propositions (1) and (2), and therefore, I think, we are bound to take them as premisses of a syllogism in the modus tollens, since (apart from certain restrictions convenient for some of the purposes of Symbolic Logic) they naturally bear this interpretation.

I admit that the case would be otherwise if, instead of 'If $C$ is true, then if $A$ is true, $B$ is not true,' we were given ' $A, B, C$, cannot be all true at once.' It is evident that Lewis Carroll has tacitly assumed, what Mr Johnson's treatment of hypotheticals assumes opeuly, that these propositions are equivalent. But this seems to involve the doctrine that a hypothetical can never be what Mr Johnson calls 'modal' (Mind, N. S. No. 1. p. 19). How then could it ever be used as major premiss, the essence of which use of a proposition is to ussert the inferribility of the consequent from the antecedent?

\section{Alfred Sidewick.}

Mr Alfred Sidgwick argues that, because a proposition occurring as clause in a hypothetical must be there regarded as possibly false and possibly true, it has in the hypothetical an import different from that of the same form of words affirmed or derived categorically. He also points out that in the modus ponens or the modus tollens the same proposition is affirmed or denied categorically, which in the hypothetical premiss is regarded as possibly false and possibly true. Hence, if Mr Sidgroick's general contention is sound, a form of words occurring as clause in a hypothetical has a different-and at the same time not a different-import from that of the same form of words occurring in a categorical. I infer from this that Mr Sidgrick's general contention is not sound. 